East African Medical Journal Vol. 77 No. 10 October 2000

TESTING A CONSENSUS CONFERENCE METHOD BY DISCUSSING THE MANAGEMENT OF TRAUMATIC DENTAL INJURIES IN TANZANIA

F.K. Kahabuka, DDS, MSc (Dar), Lecturer, Faculty of Dentistry, Muhimbili University College of Health Sciences, Dar es Salaam, Tanzania, M. K. Ntabaye, DDS (Dar), PhD (Arhus), Senior Dental Surgeon, P.O. Box 273, Dar es Salaam, Tanzania, M. van 't Hof, MSc (Utr) PhD (Nij), Professor and A. Plasschaert, DDS (Utr), PhD (Nij), Professor, Medical Faculty, College of Dental Sciences, University of Nijmegen, The Netherlands

Request for reprints to: Dr. F. K. Kahabuka, Faculty of Dentistry, P.O. Box 65014, Dar es Salaam, Tanzania.

\title{
TESTING A CONSENSUS CONFERENCE METHOD BY DISCUSSING THE MANAGEMENT OF TRAUMATIC DENTAL INJURIES IN TANZANIA
}

\author{
F.K. KAHABUKA, M. K. NTABAYE, M. van 'T HOF and A. PLASSCHAERT
}

\begin{abstract}
Objectives: To test the recommended consensus conference methods in Tanzania by discussing the management of traumatic dental injuries, and to reach consensus on the feasibility of the treatment modalities of traumatic dental injuries recommended in western countries in the Tanzanian situation.

Study participants: Fifteen dentists as representatives of the profession and two lay people as representative of potential consumers.

Interventions: Presentation of treatment modalities for traumatic dental injuries recommended in western countries.

Main outcome measure: Consensus on the feasibility of the recommended treatment modalities of traumatic dental injuries in the Tanzanian situation.

Results: For most types of injuries, consensus on the feasibility of the recommended treatment methods for Tanzania was reached immediately. More time was spent to discuss management of some injuries where the members felt that the recommended management regimes for these injuries are not feasible in the current Tanzanian situation. Panel members made three recommendations. First, parents and teachers should be provided with guidelines or instructions about self-care following trauma. Second, teaching on the management of traumatic dental injuries at training institutions should be emphasised and third, dental practitioners at dental clinics in the country should get continuing education about the management of traumatic dental injuries.

Conclusion: The methods for achieving consensus were useful in the Tanzanian dental situation, therefore it is recommended that the methods be adopted to reach consensus on other oral health issues.
\end{abstract}

\section{INTRODUCTION}

Consensus development conference methods are used as tools for solving problems in health and medicine. Their main purpose is to define levels of agreement on controversial subjects(1-3). Consensus conference methods were developed by the National Institute of Health (NIH) in the United States in 1977(4) and have been adopted and modified by a number of countries(5). Several conferences have been conducted to discuss different health issues(1). With respect to oral health, to our knowledge, only a few consensus conferences have been held to discuss oral health issues(6-8). Although a large number of conferences have been conducted, Fink(1) reported that several questions have been raised regarding the strength of consensus methods. Some questions inquire on whether the support of consensus is warranted, whether results of consensus are valid, and to what extent the consensus statements issued are disseminated. Finally, inquiries are on whether the changes in physician behaviour are associated with consensus statement. Despite these queries, Fink(1) reported that the use of consensus appears to be increasing. Steps to be set before staging the consensus conference include selection of the problem(s), selection of panel members, presenters, chairman and preparation of background information $(1,5,9)$.

According to the NIH-consensus method, it is recommended that a consensus conference begins with a plenary session, during which experts or representatives of task forces present information on the state of the science(9). Questions and comments follow presentation. The panel then convenes to reach consensus on the answers to the questions being addressed and produces a report incorporating the conclusions reached by working groups. At the final plenary session, the consensus statement is presented to the audience for comments and endorsement. After staging the conference, organisers should obtain 
professional and political support, and disseminate results of the conference to relevant bodies.

The current consensus conference was organised in response to the findings of a previous study that investigated initial treatment for traumatic dental injuries provided by dental practitioners in Tanzania(10). In this study dental practitioners frequently reported to extract the injured teeth and to prescribe antibiotics. Furthermore, the reported treatments were rated into "correct", "unnecessary" and "wrong", based on recommendations advocated in western countries. The results of this rating showed that one third of the reported treatment options were correct, one third were unnecessary and the other third were wrong. Bearing in mind that the success in the management of traumatic dental injuries depends among other things on the knowledge, experience and dedication of dental practitioners, the findings of this study stimulated the investigators to organise a consensus conference. Although there is a lot known about consensus conference, there is no information as to whether a consensus conference has been conducted in the African setting. The aim of this conference was therefore to test the recommended methods in Tanzania by discussing the management of traumatic dental injuries and to reach consensus on how far the treatment modalities of traumatic dental injuries recommended in western countries are feasible in the Tanzanian situation. In this paper the methodology as used is described and the experiences are analysed.

\section{MATERIALS AND METHODS}

Pre-panel process: Most countries spend between six months and one year planning for a consensus conference. Six months were spent to prepare the current conference in selecting information and to find the optimal setting.

Selection of the topic: The current topic was selected after observing the treatment modalities of traumatic dental injuries among dental practitioners of which one third was wrong and one-third unnecessary(10). In another study(11), few injuries to hard dental tissues were being treated at the University teaching hospital, giving a speculation that most injuries to hard dental tissues are left untreated. Due to the above reasons, the prevailing situation on management of oral-dental injuries was thought to require improvement. The topic was considered appropriate and of potential importance to dental public health in Tanzania.

Selection of panel members: It has been recommended that principal participants of a consensus conference should be representatives of the profession or have power to implement the findings and that whenever possible, potential consumers should be included $(1,2,9)$. The panel of the current conference was therefore formed by Regional Dental Officers, Heads of Dental teaching institutions, and two lay persons as representatives of caretakers for future patients (a parent and a primary school teacher). Twenty five individuals were invited to the conference of which, fifteen dentists, and the two lay people attended the conference. The fifteen dentists comprised the Chief Dental Officer, ten Regional Dental Officers, three heads of Dental Schools, and a co-ordinator of the Paedodontics course at the Faculty of Dentistry.

Selection of facilitators/presenters/chairman: There were two conference facilitators. A specialist in paediatric dentistry,
Dr. W. Berendsen (WB) and a specialist in endodontics, Dr J. P. Bressers (JPB) from the University of Nijmegen in the Netherlands. The chairman was identified in accordance to recommendations $(1,3)$ that the qualifications of panel chair should be fairly general: stature as a scientist and leadership, and that he/she must have no established opinions on the technology under consideration. Consequently, the Chief Dental Surgeon in Tanzania (Dr. HJ Mosha) was selected to chair the conference.

Information for participants: An invitation letter and literature concerning recommended treatment methods of traumatic dental injuries were mailed to all panel members, one month before the conference (the material is available from the first author)

Consensus panel meeting (conduct of the conference): The conference was conducted at Muhimbili University College of Health Sciences, in Dar es Salaam on 2nd and 3rd March 1998. A day before the conference, the facilitators, the chairman of the conference and the organisers held an executive session to discuss the logistics of the conference. A draft of a table to record the discussion as prepared by the organisers (FKK and MKN), was presented together with a conference programme. The draft and programme were reviewed and finalised.

The conference adopted the recommended steps $(1,3,9)$. On the first day, the first facilitator (WB) presented the classification, aetiology, epidemiology and examination of traumatic dental injuries. Later, the second facilitator (JPB) gave a presentation on the recommended treatment methods of injuries to the hard tissues, soft tissue injuries and of injuries to the supporting structures in the permanent dentition. Panel members discussed the presentation and recommended treatment methods for each type of injury, and their feasibility in the Tanzanian situation.

On the second day, the first facilitator (WB) presented the treatment methods of traumatic injuries in the primary dentition. Panel members discussed the presentation and recommended treatment methods for each traumatic injury in the primary dentition and their feasibility in the Tanzanian situation. After the presentation and discussion, a draft of recommended treatment for traumatic dental injuries (in primary and permanent dentition) as well as the suggested treatment methods feasible for Tanzania was printed and distributed to all panel members. The draft was equivalent to what is presented in Table 2. Panel members were given time individually to read the recommendations and prepare their final contributions. After individual reading, members convened again and made final recommendations of treatment methods for traumatic dental injuries feasible in Tanzania.

\section{RESULTS}

Treatment modalities feasible in Tanzania: For most types of injuries, consensus on treatment methods feasible for Tanzania was reached immediately. However, panel members spent more time to discuss management of some injuries where the members felt that the recommended management regimes for these injuries are not feasible in the current Tanzanian situation (Table 1). The main reasons for this perspective were mainly unavailability of materials and equipment required to treat the injuries, and lack of community awareness. Other reasons were said to be lack of or unreliable electricity supply (Table 2). Most panel members felt that it was necessary to give antibiotics as a preventive measure against secondary infection. After a long discussion, it was agreed that antibiotics are necessary only for medically compromised patients. 
Table 1

Types of injury ranked according to ease of reaching consensus on their management

\begin{tabular}{|c|c|c|c|}
\hline Injury & Immediate consensus & $\begin{array}{l}\text { Relatively } \\
\text { easy to reach consensus }\end{array}$ & $\begin{array}{c}\text { More time } \\
\text { needed to reach consensus }\end{array}$ \\
\hline Enamel fracture & $\mathrm{X}$ & & \\
\hline Crown root fracture of deciduous teeth & $\mathrm{X}$ & & \\
\hline Uncomplicated crown-root fracture of permanent teeth & $\mathrm{X}$ & & \\
\hline Complicated crown-root fracture of permanent teeth & $\mathrm{X}$ & & \\
\hline Root fracture of deciduous teeth & $\mathrm{X}$ & & \\
\hline Concussion & $\mathrm{X}$ & & \\
\hline Sub-luxation (loosening) & $\mathrm{X}$ & & \\
\hline Avulsion of deciduous teeth & $\mathrm{X}$ & & \\
\hline Lateral luxation of deciduous teeth & $\mathrm{X}$ & & \\
\hline Lateral luxation of permanent teeth & & $\mathrm{X}$ & \\
\hline Intrusive luxation of deciduous teeth & & $\mathrm{X}$ & \\
\hline Extrusive luxation of deciduous teeth & & $\mathrm{X}$ & \\
\hline Alveolar fracture & & $\mathrm{X}$ & \\
\hline Soft tissue injuries & & $\mathrm{X}$ & \\
\hline Enamel infraction & & & $\mathrm{X}$ \\
\hline Uncomplicated enamel dentine fracture & & & $\mathrm{X}$ \\
\hline Complicated enamel dentine fracture & & & $\mathrm{X}$ \\
\hline Horizontal root fracture of permanent teeth & & & $\mathrm{X}$ \\
\hline Intrusive luxation of permanent teeth & & & $\mathrm{X}$ \\
\hline Extrusive luxation of permanent teeth & & & $\mathrm{X}$ \\
\hline Avulsion of permanent teeth & & & $\mathrm{X}$ \\
\hline
\end{tabular}

Table 2

Table 2a: Recommended treatment for crown and root fractures

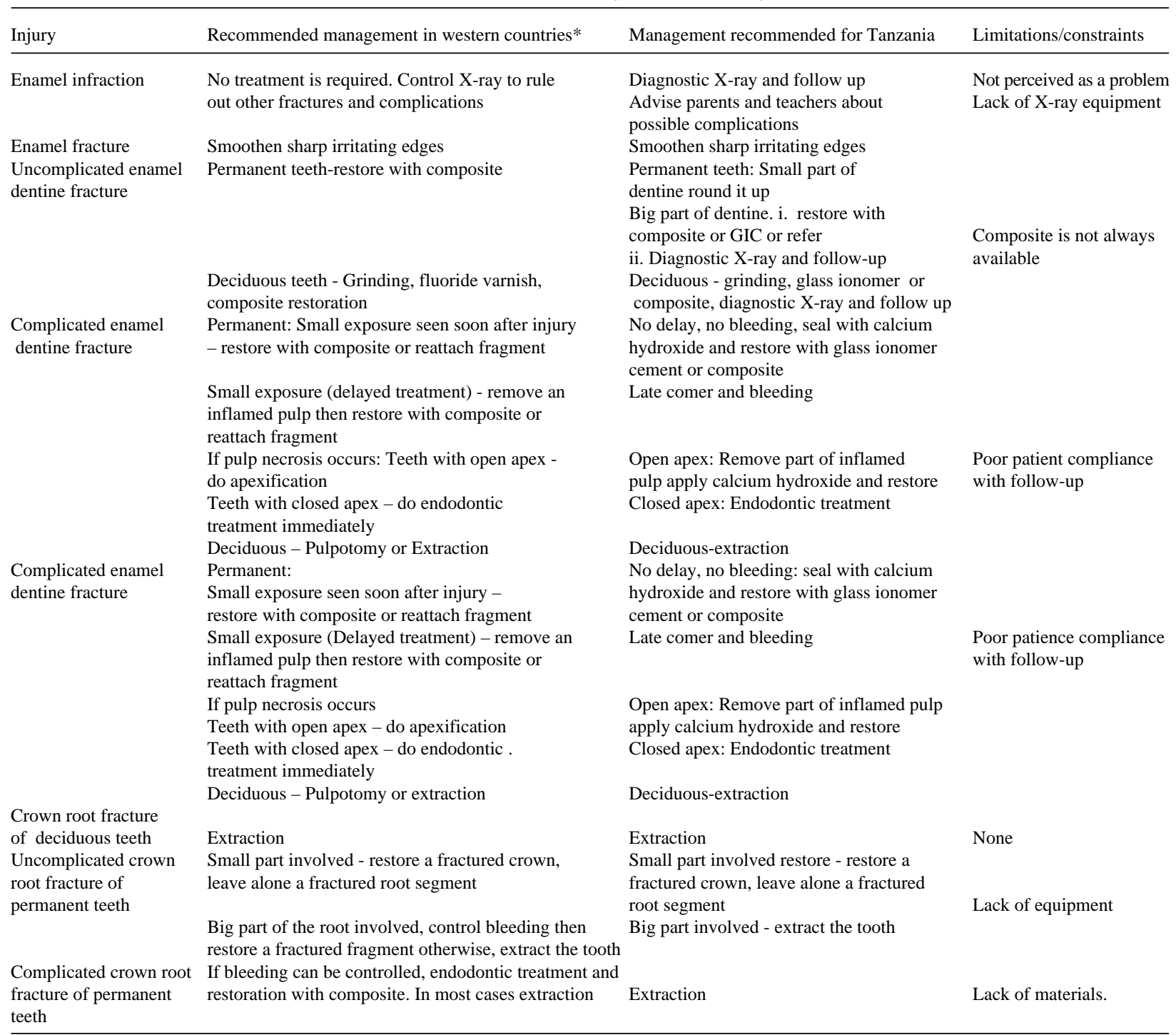


Table 2b

Recommended treatment for root fractures and luxation injuries

\begin{tabular}{|c|c|c|c|}
\hline Injury & Recommended management in western countries* & Management recommended for Tanzania & Limitations/constraints \\
\hline \multirow{3}{*}{$\begin{array}{l}\text { Root fracture of } \\
\text { deciduous teeth } \\
\text { Horizontal root fracture } \\
\text { of permanent teeth } \\
\text { Concussion }\end{array}$} & Extraction of coronal part & Extraction of coronal part & \multirow{3}{*}{$\begin{array}{l}\text { None } \\
\text { Uncertainty in availability } \\
\text { of materials }\end{array}$} \\
\hline & No mobility - rigid splint $\mathrm{x}$-ray is essential & $\begin{array}{l}\text { No mobility - no treatment, control x-ray } \\
\text { and follow up }\end{array}$ & \\
\hline & $\begin{array}{l}\text { In case pulp necrosis occurs do endodontic } \\
\text { treatment of coronal part and extract the apical part }\end{array}$ & $\begin{array}{l}\text { Mobility present - splint the tooth with } \\
\text { composite or cold cure. Control x-ray } \\
\text { and follow up }\end{array}$ & \\
\hline $\begin{array}{l}\text { Sub-luxuation } \\
\text { (loosening) }\end{array}$ & $\begin{array}{l}\text { No treatment is required. Advise good oral } \\
\text { hygiene, follow up } \\
\text { No treatment is required. Advise good oral hygiene, } \\
\text { follow-up. In case of occlusal interference, } \\
\text { relieve occlusion. Follow up }\end{array}$ & $\begin{array}{l}\text { No treatment is required. Advise good } \\
\text { oral hygiene, follow up } \\
\text { No treatment is required. Advise good } \\
\text { oral hygiene, follow up. In case } \\
\text { of occlusal interference, relieve occlusion. } \\
\text { Follow up. }\end{array}$ & None \\
\hline $\begin{array}{l}\text { Lateral luxation of } \\
\text { deciduous teeth }\end{array}$ & $\begin{array}{l}\text { Usually no treatment is required if the crown is } \\
\text { displaced lingualy and apex displaced labialy. If } \\
\text { the tooth is displaced into the tooth germ, extraction } \\
\text { is the treatment of choice. Follow up. }\end{array}$ & Extraction & Lack of X-ray machine. \\
\hline $\begin{array}{l}\text { Lateral luxation of } \\
\text { permanent teeth }\end{array}$ & $\begin{array}{l}\text { Reposition the tooth. In case of complications, } \\
\text { do endodontic treatment }\end{array}$ & $\begin{array}{l}\text { Reposition the tooth. In case of } \\
\text { complications, do endodontic treatment }\end{array}$ & None \\
\hline $\begin{array}{l}\text { Intrusive luxation of } \\
\text { deciduous teeth }\end{array}$ & $\begin{array}{l}\text { No permanent tooth germ involvement, await } \\
\text { re-erruption in two months. If intruded towards } \\
\text { the germ, extract the tooth. } \\
\text { Follow up }\end{array}$ & $\begin{array}{l}\text { No permanent tooth germ involvement, } \\
\text { chlorhexidine mouthwash for four days. } \\
\text { If intruded towards the germ, extract the tootl } \\
\text { Follow-up }\end{array}$ & \\
\hline $\begin{array}{l}\text { Intrusive luxation of } \\
\text { permanent teeth }\end{array}$ & $\begin{array}{l}\text { Await for spontaneous re-eruption. If it does not } \\
\text { occur in one and a half months, do orthodontic } \\
\text { extrusion } \\
\text { Closed apex do endodontic treatment } \\
\text { Open apex do follow up }\end{array}$ & $\begin{array}{l}\text { Extrude the tooth with a forceps, apply } \\
\text { a flexible splint for } 7 \text { to } 10 \text { days (using } \\
\text { available materials e.g. manila, fishing } \\
\text { line or iron wire), do endodontic treatment } \\
\text { before removing the splint }\end{array}$ & $\begin{array}{l}\text { It is difficult for patients } \\
\text { to come back for follow- } \\
\text { up on routine appointments. } \\
\text { Lack of thin wire, plastic } \\
\text { string and composite. }\end{array}$ \\
\hline $\begin{array}{l}\text { Extrusive luxation of } \\
\text { deciduous teeth }\end{array}$ & Extraction & Extraction & None \\
\hline $\begin{array}{l}\text { Extrusive luxation of } \\
\text { permanent teeth }\end{array}$ & $\begin{array}{l}\text { Reposition the tooth. Flexible splinting for } 7 \text { to } \\
10 \text { days. In case of pulp necrosis do endodontic } \\
\text { treatment }\end{array}$ & $\begin{array}{l}\text { Reposition the tooth. Flexible splint } \\
\text { (using available materials e.g. manila, } \\
\text { fishing line or iron wire) for } 7 \text { to } 10 \text { days. } \\
\text { In case of pulp necrosis do endodontic treatm }\end{array}$ & $\begin{array}{l}\text { Lack of thin wire, plastic } \\
\text { string and composite. } \\
\text { ent. }\end{array}$ \\
\hline
\end{tabular}

*References (12-15)

Table 2c

Recommended treatment for avulsion, alveolar fractures and soft tissue injuries

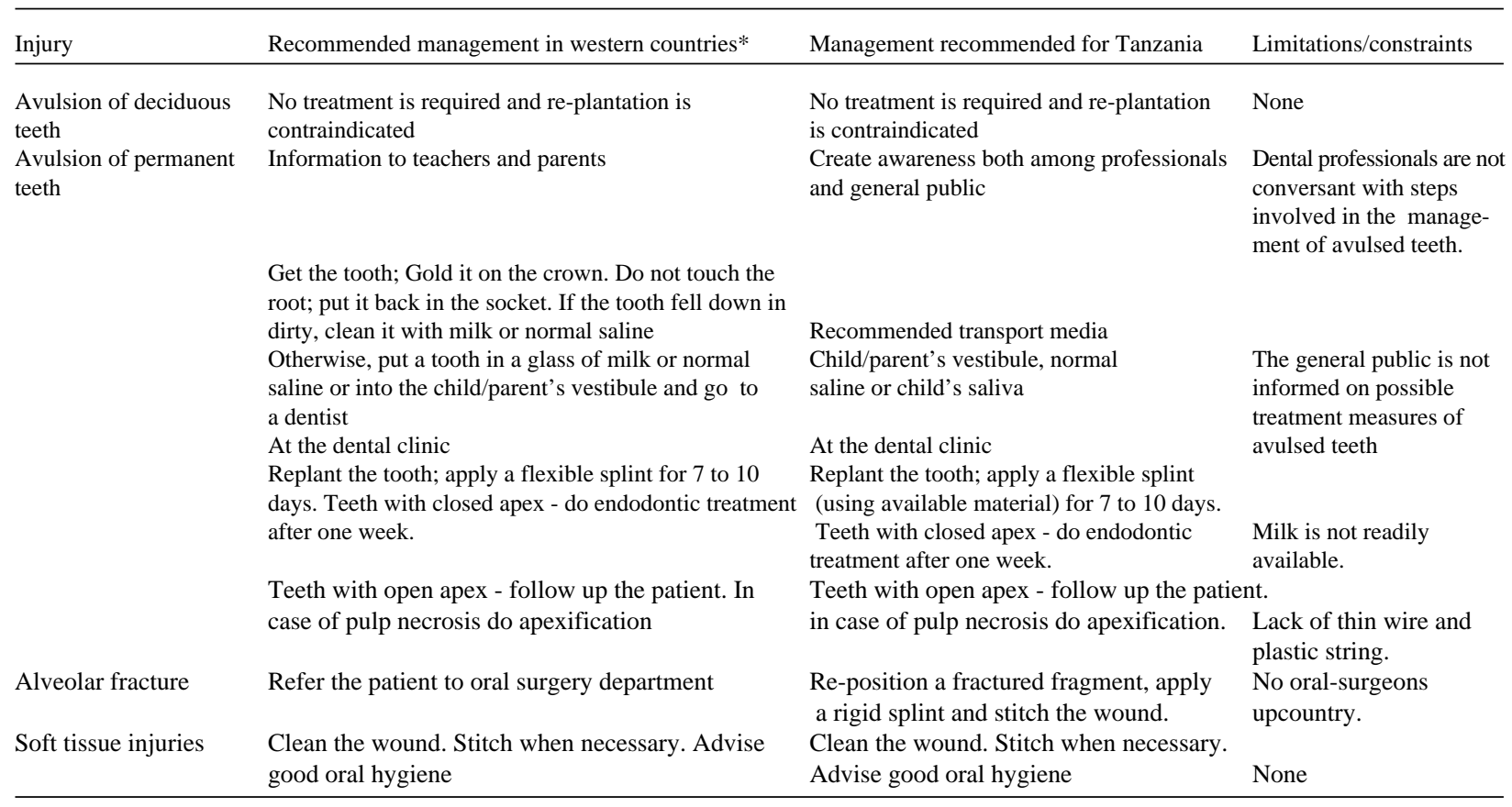

*References (12-15) 
Ratification of a consensus statement: The consensus statement was submitted to the Chief Dental Surgeon (CDS) for ratification. In Tanzania dental clinics and a large workforce is owned by the Government and thus under the administration of the CDS. Therefore, ratification from him was considered adequate. A statement of ratification was received from the Chief Dental Surgeon.

Dissemination of a consensus statement: After ratification, the consensus statement was distributed to all dental practitioners in Tanzania and was made available in the Library of the Faculty of Dentistry. In addition, it is planned that the statement will be presented during one of the scientific conferences of the Tanzania Dental Association. To investigate the willingness to use the consensus statement, all 209 dental practitioners were provided with the consensus statement and were requested about their willingness. Fifty seven per cent (57\%) of the dentists responded and indicated their intention to use the consensus statement.

\section{DISCUSSION}

This conference was the first consensus meeting to be held in Tanzania to discuss an oral health problem. Fifty eight per cent of invited members attended the conference. It was learnt that the main reason for non-attendance was communication problems. The conference lasted for two days, the duration recommended by founders of consensus methodology(1-4). Panel members participated actively in the discussion and consensus was reached. Most panel members perceived the conference as a continuing education session. This provides a difference between the current conference and previous conferences conducted elsewhere whereby experts of a certain specialty meet to resolve a controversy issue.

During the discussions, dental practitioners revealed that most Tanzanians would not perceive crown fractures as a medical/dental problem especially when there are no soft tissue injuries. Therefore lack of awareness may contribute to delay in seeking dental consultation. Members reported lack of equipment and materials as well as limited knowledge and experience to be stumbling blocks in early management of traumatic dental injuries. These problems together with lack of community awareness influence the choice of treatment.

Although an obvious gap was observed between the facilitators' knowledge and experience, and that of panel members, a calm discussion prevailed and consensus was reached. The difference in knowledge may have influenced the validity of the consensus statement since Tanzanian dental practitioners had a limited contribution. Therefore a follow up investigation seems inevitable.

In addition to reaching consensus, panel members made three recommendations to facilitate proper management of traumatic dental injuries. The first recommendation was that parents and teachers should be provided with guidelines or instructions about self-care following trauma. Accordingly, guidelines for school teachers were prepared and distributed to primary schools in one region. The effectiveness of these guidelines will be assessed. Using results from this assessment, a wider coverage of the country will be planned. Guidelines for parents will be prepared later. A second recommendation was that teaching on the management of traumatic dental injuries should be emphasised at training institutions, namely, the Faculty of Dentistry and the Assistant Dental Officers' School. Implementation of this recommendation has started at the Faculty of Dentistry while efforts will be made to emphasise teaching at the Assistant Dental Officers' School. The third recommendation was that Dental practitioners at dental clinics in the country should get continuing education about the management of traumatic dental injuries. The Chief Dental Officer is planning a continuing education workshop for dental practitioners.

The methods in the current consensus conference followed recommendations derived from literature $(1,3,9)$, with the exception that the seminar participants were not experts in the area under study. Instead, they were the professional administrators who will be influential in supporting dissemination of the consensus statement and the related recommendations. This variance was due to the fact that the controversy issue on the management of dental trauma was reported by investigators, unlike in literature where controversy arises from the practitioners themselves. Besides, in Tanzania there are no experts in the management of dental trauma. Despite this deviation, the outcome of the conference shed light on the reasons behind the treatment choices provided by Tanzanian dental practitioners and the apparent difference for the recommendation from the treatment modalities recommended in western countries.

The consensus statement (Table 2) was made available to all relevant parties. Therefore, it is expected that the statement will influence dental practitioners' choice of treatment modalities. However, changing of any behaviour requires constant reinforcement. Besides, the authors can not guarantee the actual use, instead they will continue to motivate practitioners to refer to the consensus statement whenever a patient with trauma seeks dental consultation at their clinics. A follow up study to assess the effectiveness of the dissemination is recommended.

The methods for achieving consensus used in the current conference were found to be useful for the Tanzanian situation. It is recommended therefore that the methods be adopted for other oral health issues requiring a solution. However, it is proposed that in future, organisers of a conference should prepare a list of controversy issues, send the list to potential participants to give them an opportunity to participate in selecting a topic for discussion.

\section{ACKNOWLEDGEMENTS}

The authors thank Dr H.J. Mosha for chairing the conference, Dr W. Berendsen and. Dr J.P. Bressers for facilitating the conference and all panel members for their participation. The University of Nijmegen through the WHO Collaborating Center for Oral Health Planning and future scenarios sponsored the conference. 


\section{REFERENCES}

1. Fink, A., Kosecoff, J., Chassin, M., and Brook, R.H. Consensus methods: characteristics and guidelines for use. Amer J. Public Health 1984; 74:979-83.

2. From the NIH, The Biomedical research community: Its place in consensus development. J Amer Med Assoc. 1978; 239:485-8

3. Kosecoff, J., Kanouse, D.E., Rogers, W.H., McCloskey, L., Winslow, C.M., and Brook, R. Effects of the National Institutes of health consensus development program on Physician practice. J. Amer Med Assoc. 1987; 258:2708-13

4. Jacoby, I. The consensus development program of the National Institutes of Health. Technology assessment reports. Int J Technol Assess Health Care. 1985; 1:420-32.

5. McGlynn, E.A., Kosecoff, J., and Brook, R.H. Format and conduct of consensus development conferences multination comparison. Int J Technol Assess Health Care. 1990; 6:450-69.

6. NIH consensus development conference for removal of third molar. J Oral Surg. 1980; 30:235-6

7. Limeback, H., Ismail, A., Banting, D., DenBesten, P., Featherstone, J., and Riordan, P.J. Canadian consensus conference on the appropriate use of fluoride supplements for the prevention of dental caries in children. J Can Dent Assoc. 1998; 64:636-9

8. Proceedings of the consensus conference of the Canadian Dental Association. Appropriate use of fluoride supplements for the prevention of dental caries. Comm Dent Oral Epidemiol. 1999; 27-83.

9. Perry, S., and Kalberer, J.T. The NIH consensus-development program and the assessment of health-care technologies. N. Eng J. Med . 1980; 303:169-72.

10. Kahabuka, F.K., Willemsen, W., van't Hof, M.A., Ntabaye, M.K., Burgesdijk, R., Frankenmolen, F., et al. Initial treatment of traumatic dental injuries by dental practitioners. Endod Dent Traumatol 1998; 14:206-9.

11. Kahabuka, F.K., Willemsen, W., van't Hof, M.A., Ntabaye, M.K. Plasschaert, A. and Frankenmolen, F., et al. Oral-dental injuries and their management among children and adolescents in Tanzania. East Afr Med J. 1999; 76:39-41

12. Andreasen, J.O. Treatment of fractured and avulsed teeth. J. Dent Child. 1971; 38:29-48.

13. Andreasen, J.O. and Andreasen, F.M. Textbook and colour atlas of traumatic injuries to the teeth. 3rd Ed, Munksgaard, 1994

14. McTigue, D.J. Managing traumatic injuries in the primary dentition and in the young permanent dentition. In Pinkham, J.R. Paediatric Dentistry: Infancy through adolescence. 2nd ed Philadelphia W.B. Saunders Company, 1994, p 209-22, 492-504.

15. American Association of Endodontics: Recommended guidelines for treatment of the avulsed permanent tooth. Dent Clin North Amer 1995; 39:221-5. 